Canadian

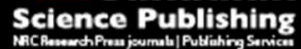

Canadian Journal of Physiology and Pharmacology Revue canadienne de physiologie et pharmacologie

\title{
Evidence of necroptosis in hearts subjected to various forms of ischemic insults
}

\begin{tabular}{|c|c|}
\hline Journal: & Canadian Journal of Physiology and Pharmacology \\
\hline Manuscript ID & cjpp-2016-0609.R1 \\
\hline Manuscript Type: & Review \\
\hline Date Submitted by the Author: & 15-Dec-2016 \\
\hline Complete List of Authors: & $\begin{array}{l}\text { Adameova, Adriana; Faculty of pharmacy, Comenius university in } \\
\text { Bratislava, Slovakia, Department of Pharmacology and Toxicology } \\
\text { Hrdlicka, Jaroslav; Czech Academy of Sciences, 2Institute of Physiology } \\
\text { Szobi, Adrian; Faculty of Pharmacy, Dept. of Pharmacology and Toxicology } \\
\text { Ledvényiová-Farkašová, Veronika; Institute for Heart Research, Slovak } \\
\text { Academy of Sciences, Department of cardiovascular physiology and } \\
\text { patophysiology } \\
\text { Kopaskova, Katarina; Faculty of Pharmacy, Comenius University in } \\
\text { Bratislava, Department of Pharmacology and Toxicology } \\
\text { Murarikova, Martina; nstitute for Heart Research, Slovak Academy of } \\
\text { Sciences, Department of cardiovascular physiology and patophysiology } \\
\text { Neckar, Jan; Institute of Physiology, } \\
\text { Kolar, Frantisek; Institute of Physiology, } \\
\text { Ravingerová, Táňa; Institute of Heart Research SAS, } \\
\text { Dhalla, Naranjan; Institute of Cardiovascular Sciences, }\end{array}$ \\
\hline Keyword: & $\begin{array}{l}\text { ischemia; ischemic preconditioning; heart failure; cell death; necroptosis; } \\
\text { passive necrosis }\end{array}$ \\
\hline
\end{tabular}




\title{
Evidence of necroptosis in hearts subjected to various forms of ischemic insults
}

\begin{abstract}
Adriana Adameova** ${ }^{1}$, Jaroslav Hrdlicka ${ }^{2}$, Adrian Szobi ${ }^{1}$, Veronika Farkasova ${ }^{3}$, Katarina Kopaskova $^{1}$, Martina Murarikova ${ }^{3}$, Jan Neckar ${ }^{2}$, Frantisek Kolar ${ }^{2}$, Tatiana Ravingerova ${ }^{3}$, and Naranjan S. Dhalla ${ }^{4}$
\end{abstract}

${ }^{1}$ Department of Pharmacology and Toxicology, Faculty of Pharmacy, Comenius University in Bratislava, ${ }^{2}$ Institute of Physiology, Czech Academy of Sciences, Prague, Czech Republic; ${ }^{3}$ Institute for Heart Research, Slovak Academy of Sciences and Centre of Excellence, SAS NOREG, Bratislava, Slovak Republic, ${ }^{4}$ Institute of Cardiovascular Sciences, St. Boniface Hospital Albrechtsen Research Centre, Winnipeg, Canada

*Corresponding author: Department of Pharmacology and Toxicology, Faculty of Pharmacy, Comenius University, Bratislava, Odbojarov 10, 832 32, Slovak Republic; Tel. +421 250117 366; Fax +421 250117 100; e-mail: adameova@fpharm.uniba.sk 


\begin{abstract}
Long-lasting ischemia can result in cell loss; however, repeated episodes of brief ischemia increase the resistance of the heart against deleterious effects of subsequent prolonged ischemic insult and promote cell survival. Traditionally, it is believed that the supply of blood to the ischemic heart is associated with release of cytokines, activation of inflammatory response and induction of necrotic cell death. In the past few years, this paradigm of passive necrosis as an uncontrolled cell death has been re-examined and the existence of a strictly regulated form of necrotic cell death, necroptosis, has been documented. This controlled cell death modality, resembling all morphological features of necrosis, has been investigated in different types of ischemia-associated heart injuries. The process of necroptosis has been found to be dependent on the activation of RIP1-RIP3-MLKL axis, which induces changes leading to the rupture of cell membrane. This pathway is activated by TNF- $\alpha$, which has also been implicated in the cardioprotective signaling pathway of ischemic preconditioning. Thus, this review is intended to describe the TNF- $\alpha$ mediated signaling leading to either cell survival or necroptotic cell death. In addition, some experimental data suggesting a link between heart dysfunction and the cellular loss due to necroptosis are discussed in various conditions of myocardial ischemia.
\end{abstract}

Keywords: myocardial ischemia; ischemic preconditioning; heart failure; cell death; necroptosis; passive necrosis 
https://mc06.manuscriptcentral.com/cjpp-pubs 


\section{Introduction}

In spite of the increased knowledge for the promotion of positive effects of a healthy lifestyle as well as effective therapeutical approaches, the mortality of patients with ischemia-associated heart diseases is on the rise and thus it is one of the leading causes of death worldwide. Depending on its duration, ischemia can induce reversible or irreversible cellular injury, which phenotypically manifests as cardiac contractile dysfunction, lifethreatening arrhythmias, heart failure and cardiacfibrosis. In contrast, brief periods of ischemia prior to a prolonged ischemic insult have been recognized as a cardioprotective intervention. This non-pharmacological phenomenon called "ischemic preconditioning (IPC)" is known to reduce the infarct size as well as severity of other end-points of ischemic injury via the activation of intrinsic cell-survival programs (Jennings and Reimer 1991; Kloner and Braunwald 1980; Opie 1987). Thus, the responses of the heart to ischemia are considered to be bimodal of nature. While short episodes of ischemia induce adaptation to the injury, a long ischemic insult is deleterious to the heart. With respect to prognosis, one of the key factors determining the function and overall viability of the previously ischemic cardiac tissue is the cellular loss. Since adult cardiomyocytes are terminally differentiated and have little potential for proliferation and self-renewal, the number of functional cardiac cells in the postnatal myocardium is considered to dictate the ability of the heart to mediate the excitationcontraction coupling process and adapt to the injury/stress including ischemic insult (Kajstura et al. 1998; Smith and Zhang 2015).

Until recently, apoptosis and necrosis have been reported to be involved in various types of the ischemia-induced cardiac pathologies. Apoptosis, as an ATP-dependent process, has been proposed to be activated mainly during the post-ischemic restoration of blood flow (reperfusion) while necrosis, a passive process, is believed to be associated with cardiac injury during ischemia when energy production is suppressed (Fliss and Gattinger 1996; Freude et 
al. 2000; Kajstura et al. 1996; Zhao et al. 2000). Nonetheless, the relative extents of apoptosis and necrosis in certain types of acute ischemia (global versus regional) are still a matter of intensive investigation. Furthermore, the cell loss underlying heart failure due to the myocardial infarction has been examined extensively; however, the number of apoptotic positive cells has been reported to be rather low (Adameova et al. 2016; Kang and Izumo 2000; Mani 2008).

Over the past few years, the knowledge about passive necrosis, traditionally considered an accidental process, has advanced considerably and a new form of regulated necrosis, called "necroptosis", has gained acceptance among several biologists and cardiologists (Adameova et al. 2016). Both passive necrosis and necroptosis are characterized by membranedisruption, cell integrity loss, mitochondrial dysfunction and inflammatory response in the surrounding environment; however, these processes differ in their regulation. While passive necrosis is an unregulated process, necroptosis has been shown to be strictly regulated by certain signaling pathways; this has been discussedin the following sections.

Mechanisms of necroptotic cell death and role of TNF- $\alpha$ in cell's decision to either die or promote prosurvival program

Necroptosis is a form of programmed necrosis dependent on receptor-interacting protein kinase-1 (RIP1) and/or receptor interacting protein kinase-3 (RIP3). It has been reported to be induced by stimulation of several death receptors (TNFR1, Fas, TRAIL-R, DR6 and $\mathrm{T}$ cell receptor) as well as some other triggers not associated with these stimuli (Moquin et al. 2010; Strilic et al. 2016). Current understanding of molecular mechanisms of necroptosis is largely based on experiments involving TNFR1 ligation. Normally, stimulation of TNFR1 by TNF- $\alpha$ can lead into two distinct outcomes, namely stimulation of cell survival or and occurrence of cell death. The trigger for the particular TNF- $\alpha$-mediated pathway is 
determined by posttranslational modification of RIP1 (Figure 1). In fact, polyubiquitination of RIP1 (especially at residue Lys ${ }^{377}$ in membrane-bound complex I assembled transiently) after TNFR1 activation is required for RIP1 to serve as a scaffold for the recruitment of transforming growth factor beta-activated kinase 1 (TAK1) and nuclear factor-kappa-B essential modulator (NEMO). Both TAK1 and NEMO are involved in cell survival signaling

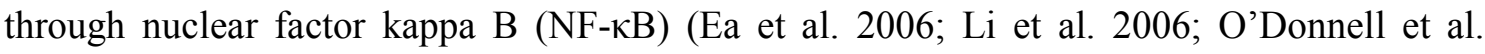
2007). This scaffolding function of RIP1 is independent of its kinase activity, unlike its role in cell death signaling (Degterev et al. 2005, 2008). The degree of activation of NF- $\mathrm{B}-$ dependent pathways after TNFR1 stimulation and the extent of RIP1 ubiquitination are finetuned by different ubiquitin-modifying enzymes, such as cellular inhibitor of apoptosis (cIAP1/2), A20 and cylindromatosis (CYLD) (Moquin et al. 2010; Vanlangenakker et al. 2010, 2011). On the other hand, in the case of increased activity of CYLD or in the absence of polyubiquitination due to cIAP1/2 loss leading into deubiquitination of RIP1, complex I internalizes and turns into cell death-promoting complex II by primarily recruiting procaspase-8 (Micheau and Tschopp 2003; Moquin et al. 2010; Schneider-Brachert et al. 2004; Vanlangenakker et al. 2010).

With the context of uninhibited caspase- 8 activity, procaspase- 8 homodimerizes, cleaves itself into an active form and mediates the apoptotic cascade while at the same time it inhibits necroptosis by cleaving RIP1 and RIP3 (Declerq et al. 2009; Feng et al. 2007; Moquin et al. 2010). When the caspase- 8 activity is insufficient, the uncleaved RIP1 retains its kinase activity thereby promoting autophosphorylation of other molecules of RIP1 and subsequent phosphorylation of RIP3 inducing necroptosis propagation (Cho et al. 2009). Once RIP3 is phosphorylated, mixed-lineage kinase domain-like protein (MLKL), a downstream of RIP3 (considered to be the most important terminal protein of necroptosis so far) is recruited to the RIP1-RIP3 complex (Sun et al. 2012; Wu et al. 2012). These phosphorylation events of 
MLKL at $\mathrm{Thr}^{357}$ and/or $\operatorname{Ser}^{358}$ induce a conformational change, which triggers MLKL oligomerization and its translocation to membrane compartments likely due to electrostatic interactions between its conserved positively charged regions and negative headgroups of membrane phospholipids (Sun et al. 2012; Quarato et al. 2016; Wang et al. 2014). Current evidence suggests that once MLKL oligomers are assembled in membranes, these essentially act as either non-specific pores (Dondelinger et al. 2014; Wang et al. 2014), or cation channels (Cai et al. 2014; Xia et al. 2016) for the induction of ion channel opening (Chen et al. 2014), thereby perturbing normal cellular homeostasis leading to osmotic rupture of the cell.

It should be noted that TNF- $\alpha$ is an interesting molecule for determining the final fate of the cell. Indeed, on the one hand, it is recognized as one of the key molecules initiating the activation of TNFR1-mediated necroptosis. At the same time, through a series of signaling steps, TNF- $\alpha$ activates the transcriptional factor NF- $\kappa B$ in the nucleus, which in turn triggers the inflammatory response involving production of pro-inflammatory cytokines, activation of neutrophils, and metalloproteinases (Gordon et al. 2011). Thus, pro-inflammatory environment in the settings of high levels of TNF- $\alpha$ may be a result of necroptosis- and NF$\kappa \mathrm{B}$-associated inflammation. On the other hand, TNF- $\alpha$ has also been reported to produce beneficial effects which promote cardiomyocyte survival. In fact, NF- $\kappa$, due to BNIP3 (BCL2/adenovirus E1B protein-interacting protein 3) silencing, inhibits BNIP3-dependent permeability transition pore in mitochondria and thereby inhibits cell death (Baetz et al.

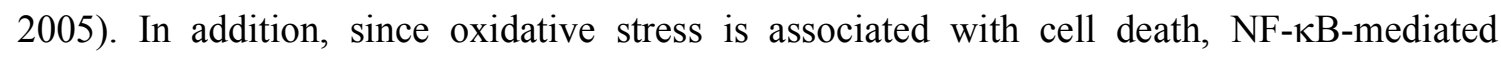
changes in gene transcription leading into an increase in the antioxidant enzymes expression also support its role in cell survival (Hikose 2009; Nelson et al. 1995). These cardioprotective effects opposing cardiac injury have been reported to be implicated in signaling responsible for increased tolerance against ischemia as evidenced in conditions of pre- and 
postconditioning (Lacerda et al. 2009; Skyschally et al. 2007) as well as in hearts adapted to hypoxia (Chytilova et al. 2015). Thus, it is plausible that a balance between TNF- $\alpha$-mediated beneficial and detrimental effects strongly depends on its actual tissue and plasmatic levels. While high levels of TNF- $\alpha$ are associated with cardiac injury, a low concentration may trigger prosurvival signaling. Because TNF- $\alpha$ is also produced by tissue, besides by cells of the immune system, the contribution of TNF- $\alpha$ from autocrine, paracrine and juxtacrine origin can participate in the final decision of cardiac cells to undergo either of the pathways. Thus, it could be hypothesized that a response of the myocardium to TNF- $\alpha$ produced by various heart cells can be different. In fact, the inflammatory cytokines, inlcuding TNF-alpha, synthetized by fibroblasts rather than by cardiomyocytes per se can undesirably affect cardiac cell morphology, and contraction capability (LaFramboise et al. 2007). A critical role of certain cells synthetizing TNF- $\alpha$ has also been reported in a study of Lambertsen et al. (2009), who showed that the microglial not leukocyte-derived cytokine determines the survival of endangered neurons in cerebral ischemia. A dual role of TNF- $\alpha$, highlighting the divergent effects of certain levels of this molecule, is also supported by findings of a clinical study using infliximab (a TNF- $\alpha$ antibody), which at a higher dose $(10 \mathrm{mg} / \mathrm{kg})$, but not a lower one (5 $\mathrm{mg} / \mathrm{kg}$ ), worsened the end-points (Chung et al. 2003).

Evidence of necroptosis in cardiac tissue subjected to ischemia and ischemia-induced necroptotic loss of cardiac cells

A wide spectrum of diseases (gout, sclerosis multiplex, amyotropic lateral sclerosis, non-alcoholic steatohepatitits, atherosclerosis, aortic aneurysms and chronic obstructive pulmonary disease) (Afonso et al. 2015; Desai et al. 2016; Mizumura et al. 2014; Meng et al. 2015; Ofengeim et al. 2015; Re et al. 2014; Wang et al. 2015), as well as disorders associated with ischemic injury have been found to be positive for necroptosis (Linkermann et al. 2012, 
2013; Northington et al. 2011; Wen et al. 2016). In accordance (as discussed below), necroptosis inhibition following acute myocardial $\mathrm{I} / \mathrm{R}$ injury has been proven to exert beneficial effects in both in vivo and ex vivo animal models. In fact, Nec-1, a widely used necroptosis inhibitor, given to mice intraperitoneally reduced the size of infarction, while Nec-1i, its inactive analogue, did not show any effect (Smith et al. 2007). Similar results were also reported after intravenous Nec-1 application in mice (Lim et al. 2007; Oerlemans et al. 2012) as well as pigs (Koudstaal et al. 2015). In ex vivo experiments, hearts perfused with Nec-1 were protected from cell death and exhibited reduced infarct development (Dmitriev et al. 2013; Koshinuma et al. 2014; Smith et al. 2007). Furthermore, the work by Luedde et al. (2014) has demonstrated that mice deficient in RIP3, a critical member of the necroptotic cascade, show a significantly improved ejection fraction, less hypertrophy and inflammatory response after permanent coronary artery ligation. These observations are concordant with a very recent study utilizing the same animal knockout model (Zhang et al. 2016). To extend this knowledge, we performed some studies investigating the extent of necroptotic cell death in both ventricles of failing hearts due to irreversible ischemia and in hearts adapted to an ischemic insult. Ischemic cardiomyopathy was found to be developed during 42 days in rats after 1-hour of the coronary ligation whereas ischemic preconditioning induced by one cycle of $5 \mathrm{~min}$ of ischemia and $5 \mathrm{~min}$ of reperfusion protected the heart following ischemia for 30 min and reperfusion for $40 \mathrm{~min}$. In the case of ischemic cardiomyopathy, the heart failure was characterized by contractile dysfunction as evidenced by depressed fractional shortening (Figure 2). In this experimental model, the expression of RIP1 and RIP3 was increased in the left ventricle; however, the expression of these markers in the right ventricle was comparable between groups (data not shown). Importantly, the terminal necroptotic protein MLKL was found to be upregulated in the left ventricle of failing hearts indicating the presence of necroptotic cell injury (Table 1). It should be, however, pointed out that the necroptotic 
cascade involved in this condition needs to be supported by detection of phoshorylated species of MLKL. In spite of this limitation, the results of this study have indicated the relevance of necroptosis in ischemic cardiomyopathy, which may underlie death of cardiomyocytes and mechanical dysfunction of the heart. On the other hand, ischemic preconditioning, which is known to improve the post-ischemic recovery of the left ventricular function (Figure 3), failed to modulate the necroptotic markers. In fact, the ventricular tissue samples from the preconditioned hearts showed no changes in protein expression of RIP1, RIP3 and MLKL as compared to those from the non-preconditioned hearts. It should be noted that the hearts subjected to $I / R$ were characterized by increased presence of some of these necroptotic markers (Table 2).

Since necroptosis is a relatively recently defined form of cell death, the mechanisms of its induction and execution in certain cardiac pathologies, including those associated with ischemia, are a potentially interesting avenue of investigation. However, in spite of the clear evidence and relevance of necroptosis in myocardial I/R damage, the mechanisms involved in the necroptosis initiation or development are not very well understood and in fact, the reported observations are conflicting. Early studies investigating necroptosis in myocardial I/R have indicated that necroptosis was associated with mitochondrial permeability transition pore (MPTP) opening, a mitochondrial process that has been implicated in the I/R-induced necrosis long before the discovery of necroptosis (reviewed by Halestrap and Pasdois 2009). A study by Lim et al. (2007) has suggested that cardioprotection elicited by necroptosis inhibition by a small molecule RIP1 inhibitor, necrostatin-1 (Nec-1), in I/R hearts is dependent on the critical MPTP regulator protein, cyclophilin D (CypD), implying MPTP opening during necroptosis initiation and/or progression. On the other hand, the infarct size was lower in wild type mice treated with $\mathrm{Nec}-1$ than in $\mathrm{CypD}^{-/-}$mice treated or untreated with Nec-1, arguing against such a simple explanation. In partial agreement with these results is a 
recent study by Zhang et al. (2016) who have shown RIP3-dependent necroptosis either due to I/R or doxorubicin-induced cardiotoxicity being partially mediated by CypD-sensitive MPTPinduced mitochondrial depolarization. Importantly, this study has also implicated the activation of $\mathrm{Ca}^{2+}$-calmodulin dependent protein kinase II (CaMKII) in necroptosis. The involvement of this key regulator of $\mathrm{Ca}^{2+}$ homeostasis in cardiomyocytes in myocardial I/Rinduced necroptosis has also been proposed in our study showing that the inhibition of CaMKII reversed certain changes in pronecroptotic markers and improved contractile function (Szobi et al. 2014).

The discordant finding of the study by Zhang et al. (2016) suggests that cardiomyocyte necroptosis relies on neither RIP1 nor MLKL, which goes against all studies utilizing RIP1 inhibition as their cardioprotective antinecroptotic intervention of choice. Indeed, it is hard to reconcile these data with observations reported by Oerlemans et al. (2012), who successfully co-immunoprecipitated the canonical RIP1-RIP3-MLKL complex from the left ventricle of a mouse myocardial infarction model, which was further responsive to RIP1 inhibition. While these studies have been vital in describing the downstream signaling after necroptosis activation, initiating triggers in the setting of myocardial $\mathrm{I} / \mathrm{R}$ are essentially unknown. Recently, microRNAs (miR) have emerged as possible modulators of necroptosis initiation during I/R (Qin et al. 2016). In fact, it has been reported that miR-233 KO mice show enhanced expression of primary necroptotic machinery proteins while the converse is true for transgenic miR-233 overexpressing mice. Likewise, these changes have also been correlated with cardiac resistance against I/R-induced necroptosis. Importantly, this study has identified death receptors TNFR1 and DR6 as targets of miR-233, both of which have been previously shown to initiate necroptosis (Degterev et al. 2008; Strilic et al. 2016).

Pharmacological modulation of necroptosis 
Targeting molecules of the TNFR1-RIP1-RIP3-MLKL signaling cascade has been suggested to mitigate cardiac injury due to necroptosis. Although the most effective prevention of necroptosis seems to be inhibition of MLKL, the use of the only available MLKL inhibitor, necrosulfonamide, is limited by its species-selective action as it interacts with $\mathrm{Cys}^{86}$ which has not been detected in mouse or rat MLKL (Sun et al. 2012). Thus, in experimental studies employing small laboratory animals, the most used modulators of necroptosis are the inhibitors of RIP1, which are referred to as necrostatins. Nec-1, a widely used inhibitor, acts as a selective allosteric inhibitor of kinase domain of RIP1, while other necrostatins, Nec-3, -4 and -5 , inhibit RIP1 through mechanisms distinct from the effects of Nec-1. Interestingly, Nec-1 also inhibits the potent immunomodulatory enzyme indoleamine 2,3-dioxygenase (IDO) thereby possessing the capability of modulating the tissue injury independently of RIP1 inhibition. Its inactive variant Nec-1i lacks the RIP1-targeting effects, however, it retains the ability to inhibit IDO (Degterev et al. 2013; Takahashi et al. 2012). In addition, we have recently reported that Nec-1 likely exerts off-target pharmacodynamic effects modulating basal heart function (Szobi et al. 2016). In fact, after a bolus application, Nec-1 increased systolic and diastolic blood pressure as well as heart rate. Likewise, analysis of ECG changes revealed the capability of Nec-1 to promote faster conduction of the impulses through atria to the ventricles. To avoid misinterpretation of data which may arise from these off-target effects, the use of an inhibitor being selective for RIP1 with no additional action is highly warranted. Nec-1s, a Nec-1 analogue inhibiting RIP1 while not affecting IDO or other intracellular molecules, seems to represent the most specific and appropriate pharmacological tool for the study of necroptosis in animals (Degterev et al. 2013; Takahashi et al. 2012).

\section{Conclusions}

Ischemia, depending on the duration and type, can act as a bimodal process as it 
induces adaptive response for the activation of survival signaling or produces reversible/irreversible injury leading to a significant loss of cardiac cells. Although passive necrosis and apoptosis are generally associated with ischemia-mediated cardiac injury, necroptosis, which shares certain features of both these forms of cell death, has recently been reported to determine the extent of viable myocardium after ischemic insults. In fact, the major necroptotic markers, RIP3 and MLKL, have been documented being upregulated in hearts subjected to acute ischemia followed by reperfusion. Likewise in post-infarcted failing rat hearts, these upregulated markers have been suggested to contribute to adverse cardiac remodeling and underlie disturbances in contractile function. In contrast, the inhibition of RIP1 by necrostatins has been reported to be capable of mitigating the injury and preventing the contractile dysfunction. Interestingly, a brief episode of ischemia before a more prolonged ischemic insult has been shown to limit the infarct size and abolish cardiac stunning; however, this ischemic preconditioning did not modulate the expression of these pronecroptotic proteins. Thus, it appears that the elevated levels of RIP3 and MLKL are the only definite criteria to distinguish necroptosis from other forms of cell death due to passive necrosis and apoptosis. It can also be concluded that cardiac tissue injured by acute ischemia, as well as post-infarction cardiomyopathy is positive for necroptosis while the heart subjected to ischemic preconditioning is unlikely to be directly protected from necroptosis. However, with respect to the progression of necroptosis, these findings should ideally be supported by immunohistochemical and/or immunoprecipitation investigations. From the foregoing discussion it is evident that necroptosis plays an important role in the loss of cardiac cells subjected to various types of ischemic insults; however, further studies are needed to investigate factors determining the exact mechanisms of necroptosis under several pathological conditions. Likewise, it is also important to investigate the exact role of TNF- $\alpha-$ coupled pathways in underlying the fate of cardiac cells to either die or survive. 


\section{Acknowledgements}

The research in this article was supported by grants from the Slovak Scientific Grant Agency (VEGA) VEGA 1/0271/16, 2/0201/15, APVV-15-607, APVV-0102-11, Slovak Society of Cardiology and from the Ministry of Health of the Czech Republic 15-27735A. The infrastructural support for this study was provided by the St. Boniface Hospital Research Foundation.

\section{References}

Adameova, A., Goncalvesova, E., Szobi, A., and Dhalla N.S. 2016. Necroptotic cell death in failing heart: relevance and proposed mechanisms. Heart Fail. Rev. 21(2): 213-221

Afonso, M.B., Rodrigues, P.M., Carvalho, T., Caridade, M., Borralho, P., Cortez-Pinto, H., Castro, R.E., and Rodrigues, C.M. 2015. Necroptosis is a key pathogenic event in human and experimental murine models of non-alcoholic steatohepatitis. Clin. Sci. 129(8): $721-739$

Baetz, D., Regula, K.M., Ens, K., Shaw, J., Kothari, S., Yurkova, N., and Kirshenbaum LA. 2005. Nuclear factor-kappaB-mediated cell survival involves transcriptional silencing of the mitochondrial death gene BNIP3 in ventricular myocytes. Circulation, 112(24): $3777-3785$

Cai, Z., Jitkaew, S., Zhao, J., Chiang, H.C., Choksi, S., Liu, J., Ward, Y., Wu, L.G., and Liu, Z.G. 2014. Plasma membrane translocation of trimerized MLKL protein is required for TNF-induced necroptosis. Nat. Cell Biol. 16: 55-65

Chen, X., Li, W., Ren, J., Huang, D., He, W.T., Song, Y., Yang, C., Li, W., Zheng, X., Chen, P., and Han, J. 2014. Translocation of mixed lineage kinase domain-like protein to plasma membrane leads to necrotic cell death. Cell Res. 24: 105-121 
Cho, Y.S., Challa, S., Moquin, D., Genga, R., Ray, T.D., Guildford, M., and Chan, F.M. 2009. Phosphorylation-driven assembly of the RIP1-RIP3 complex regulates programmed necrosis and virus-induced inflammation. Cell, 137: 1112-1123

Chung, E.S., Packer, M., Lo, K.H., Fasanmade, A.A., and Willerson, J.T. 2003. Anti-TNF Therapy Against Congestive Heart Failure Investigators. Randomized, double-blind, placebo-controlled, pilot trial of infliximab, a chimeric monoclonal antibody to tumor necrosis factor-alpha, in patients with moderate-to-severe heart failure: results of the antiTNF Therapy Against Congestive Heart Failure (ATTACH) trial. Circulation, 107(25): $3133-3140$

Chytilová, A., Borchert, G.H., Mandíková-Alánová, P., Hlaváčková, M., Kopkan, L., Khan, M.A., Imig, J.D., Kolář, F., and Neckář, J. 2015. Tumour necrosis factor- $\alpha$ contributes to improved cardiac ischaemic tolerance in rats adapted to chronic continuous hypoxia. Acta Physiol. (Oxf). 214(1): 97-108

Declercq, W., Vanden Berghe, T., and Vandenabeele, P. 2009. RIP kinases at the crossroads of cell death and survival. Cell, 138(2): 229-232

Degterev, A., Huang, Z., Boyce, M., Li, Y., Jagtap, P., Mizushima, N., Cuny, G.D., Mitchison, T.J., Moskowitz, M.A., and Yuan, J. 2005. Chemical inhibitor of nonapoptotic cell death with therapeutic potential for ischemic brain injury. Nat. Chem. Biol. 1: 112119

Degterev, A., Hitomi, J., Germscheid, M., Ch'en, I.L., Korkina, O., Teng, X., Abbott, D., Cuny, G.D., Yuan, C., Wagner, G., Hedrick, S.M., Gerber, S.A., Lugovskoy, A., and Yuan, J. 2008. Identification of RIP1 kinase as a specific cellular target of necrostatins. Nat. Chem. Biol. 4: 313-321

Degterev, A., Maki, J.L., and Yuan, J. 2013. Activity and specificity of necrostatin-1, small-molecule inhibitor of RIP1 kinase. Cell Death Differ. 20(2): 366

Desai, J., Kumar, S.V., Mulay, S.R., Konrad, L., Romoli, S., Schauer, C., Herrmann, M., Bilyy, R., Müller, S., Popper, B., Nakazawa, D., Weidenbusch, M., Thomasova, D., Krautwald, S., Linkermann, A., and Anders, H.J. 2016. PMA and crystal-induced neutrophil extracellular trap formation involves RIPK1-RIPK3-MLKL signalling. Eur. J. Immunol. 46(1): 223-229 
Dmitriev, Y.V., Minasian, S.M., Demchenko, E.A., and Galagudza, M.M. 2013. Study of cardioprotective effects of necroptosis inhibitors on isolated rat heart subjected to global ischemia-reperfusion. Bull. Exp. Biol. Med. 155: 245-248

Dondelinger, Y., Declercq, W., Montessuit, S., Roelandt, R., Goncalves, A., Bruggeman, I., Hulpiau, P., Weber, K., Sehon, C.A., Marquis, R.W., Bertin, J., Gough, P.J., Savvides, S., Martinou, J.C., Betrand, M.J., and Vandenabeele, P. 2014. MLKL compromises plasma membrane integrity by binding to phosphatidylinositol phosphates. Cell Rep. 7: 971-981

Ea, C.K., Deng, L., Xia, Z.P., Pineda, G., and Chen, Z.J. 2006. Activation of IKK by TNFalpha requires site-specific ubiquitination of RIP1 and polyubiquitin binding by NEMO. Mol. Cell, 22: 245-257

Feng, S., Yang, Y., Mei, Y., Ma, L., Zhu, D.E., Hoti, N., Castanares, M., and Wu, M. 2007. Cleavage of RIP3 inactivates its caspase-independent apoptosis pathway by removal of kinase domain. Cell. Signal. 19(10): 2056-2067

Fliss, H., and Gattinger, D. 1996. Apoptosis in ischemic and reperfused rat myocardium. Circ. Res. 79: 949-956

Freude, B., Masters, T.N., Robicsek, F., Fokin, A., Kostin, S., Zimmermann, R., Ullmann, C., Lorenz-Meyer, S., and Schaper, J. 2000. Apoptosis is initiated by myocardial ischemia and executed during reperfusion. J. Mol. Cell. Cardiol. 32: 197-208

Gordon, J.W., Shaw, J.A., and Kirshenbaum, L.A. 2011. Multiple facets of NF-кB in the heart: to be or not to NF-кB. Circ. Res. 108(9): 1122-1132

Halestrap, A.P., and Pasdois, P. 2009. The role of the mitochondrial permeability transition pore in heart disease. Biochim. Biophys. Acta, 1787(11): 1402-1415

Hikoso, S., Yamaguchi, O., Nakano, Y., Takeda, T., Omiya, S., Mizote, I., Taneike, M., Oka, T., Tamai, T., Oyabu, J., Uno, Y., Matsumura, Y., Nishida, K., Suzuki, K., Kogo, M., Hori, M., and Otsu, K. 2009. The I\{kappa\}B kinase $\{$ beta $\} /$ nuclear factor $\{$ kappa $\}$ B signaling pathway protects the heart from hemodynamic stress mediated by the regulation of manganese superoxide dismutase expression. Circ. Res. 105(1): 70-79 
Jennings, R.B., and Reimer, K.A. 1991. The cell biology of acute myocardial ischemia. Annu. Rev. Med. 42: 225-246

Kajstura, J., Cheng, W., Reiss, K., Clark, W.A., Sonnenblick, E.H.,, Krajewski, S., Reed, J.C., Olivetti, G., and Anversa, P. 1996. Apoptotic and necrotic myocyte cell deaths are independent contributing variables of infarct size in rats. Lab. Invest. 74: 86-107

Kajstura, J., Leri, A., Finato, N., Di Loreto, C., Beltrami, C.A., and Anversa, P. 1998. Myocyte proliferation in end-stage cardiac failure in humans. Proc. Natl. Acad. Sci. U.S.A. 95: 8801-8805

Kang, P.M., and Izumo, S. 2000. Apoptosis and heart failure: A critical review of the literature. Circ. Res. 86: 1107-1113

Kloner, R.A., and Braunwald, E. 1980. Observations on experimental myocardial ischaemia. Cardiovasc. Res. 14(7): 371-395

Koshinuma, S., Miyamae, M., Kaneda, K., Kotani, J., and Figueredo, V.M. 2014. Combination of necroptosis and apoptosis inhibition enhances cardioprotection against myocardial ischemia-reperfusion injury. J. Anesth. 28: 235-241

Koudstaal, S., Oerlemans, M.I., Van der Spoel, T.I., Janssen, A.W., Hoefer, I.E., Doevendans, P.A., Sluijter, J.P., and Chamuleau, S.A. 2015. Necrostatin-1 alleviates reperfusion injury following acute myocardial infarction in pigs. Eur. J. Clin. Invest. 45: 150-159

LaFramboise, W.A., Scalise, D., Stoodley, P., Graner, S.R., Guthrie, R.D., Magovern, J.A., and Becich, M.J. 2007. Cardiac fibroblasts influence cardiomyocyte phenotype in vitro. Am. J. Physiol. Cell. Physiol. 292: C1799-808

Lambertsen, K.L., Clausen, B.H., Babcock, A.A., Gregersen, R., Fenger, C., Nielsen, H.H., Haugaard, L.S., Wirenfeldt, M., Nielsen, M., Dagnaes-Hansen, F., Bluethmann, H., Faergeman, N.J., Meldgaard, M., Deierborg, T., and Finsen, B. 2009. Microglia protect neurons against ischemia by synthesis of tumor necrosis factor. J. Neurosci. 29: 13191330

Lacerda, L., Somers, S., Opie, L.H., and Lecour, S. 2009. Ischaemic postconditioning 
protects against reperfusion injury via the SAFE pathway. Cardiovasc. Res. 84: 201-208

Li, H., Kobayashi, M., Blonska, M., You, Y., and Lin, X. 2006. Ubiquitination of RIP is required for tumor necrosis factor alpha-induced NF-kappaB activation. J. Biol. Chem. 281: 13636-13643

Lim, S.Y., Davidson, S.M., Mocanu, M.M., Yellon, D.M., and Smith, C.C. 2007. The cardioprotective effect of necrostatin requires the cyclophilin-D component of the mitochondrial permeability transition pore. Cardiovasc. Drugs Ther. 21: 467-469

Linkermann, A., Bräsen, J.H., Himmerkus, N., Liu, S., Huber, T.B., Kunzendorf, U., and Krautwald, S. 2012. Rip1 (receptor-interacting protein kinase 1) mediates necroptosis and contributes to renal ischemia/reperfusion injury. Kidney Int. 81(8): 751-761

Linkermann, A., Bräsen, J.H., Darding, M., Jin, M.K., Sanz, A.B., Heller, J.O., De Zen, F., Weinlich, R., Ortiz, A., Walczak, H., Weinberg, J.M., Green, D.R., Kunzendorf, U., and Krautwald, S. 2013. Two independent pathways of regulated necrosis mediate ischemia-reperfusion injury. Proc. Natl. Acad. Sci. U.S.A. 110(29): 12024-12029

Luedde, M., Lutz, M., Carter, N., Sosna, J., Jacoby, C., Vucur, M., Gautheron, J., Roderburg, C., Borg, N., Reisinger, F., Hippe, H.J., Linkermann, A., Wolf, M.J., RoseJohn, S., Lullmann-Rauch, R., Adam, D., Flogel, U., Heikenwalder, M., Luedde, T., and Frey, N. 2014. RIP3, a kinase promoting necroptotic cell death, mediatesadverse remodelling after myocardial infarction. Cardiovasc. Res. 103: 206-216

Mani, K. 2008. Programmed cell death in cardiac myocytes: strategies to maximize postischemic salvage. Heart Fail. Rev. 13: 193-209

Meng, L., Jin, W., and Wang, X. 2015. RIP3-mediated necrotic cell death accelerates systematic inflammation and mortality. Proc. Natl. Acad. Sci. U.S.A. 112: 11007-11012

Micheau, O., and Tschopp, J. 2003. Induction of TNF receptor I-mediated apoptosis via two sequential signaling complexes. Cell, 114: 181-190

Mizumura, K., Cloonan, S.M., Nakahira, K., Bhashyam, A.R., Cervo, M., Kitada, T., Glass, K., Owen, C.A., Mahmood, A., Washko, G.R., Hashimoto, S., Ryter, S.W., and 
Choi, A.M. 2014. Mitophagy-dependent necroptosis contributes to the pathogenesis of COPD. J. Clin. Invest. 124: 3987-4003

Moquin, D., and Chan, F.K. 2010. The molecular regulation of programmed necrotic cell injury. Trends. Biochem. Sci. 35: 434-441

Nelson, S.K., Wong, G.H., and McCord, J.M. 1995. Leukemia inhibitory factor and tumor necrosis factor induce manganese superoxide dismutase and protect rabbit hearts from reperfusion injury. J. Mol. Cell. Cardiol. 27(1): 223-229

Northington, F.J., Chavez-Valdez, R., Graham, E.M., Razdan, S., Gauda, E.B., and Martin, L.J. 2011. Necrostatin decreases oxidative damage, inflammation, and injury after neonatal HI. J. Cereb. Blood Flow Metab. 31: 178-189

O'Donnell, M.A., Legarda-Addison, D., Skountzos, P., Yeh, W.C., and Ting, A.T. 2007. Ubiquitination of RIP1 regulates an NF-kappaB-independent cell-death switch in TNF signaling. Curr. Biol. 17: 418-424

Oerlemans, M.I., Liu, J., Arslan, F., den Ouden, K., Van Middelaar, B.J., Doevendans, P.A., and Sluijter, J.P. 2012. Inhibition of RIP1-dependent necrosis prevents adverse cardiac remodeling after myocardial ischemia-reperfusion in vivo. Basic. Res. Cardiol. 107: 270

Ofengeim, D., Ito, Y., Najafov, A., Zhang, Y., Shan, B., DeWitt, J.P., Ye, J., Zhang, X., Chang, A., Vakifahmetoglu-Norberg, H., Geng, J., Py, B., Zhou, W., Amin, P., Berlink, Lima. J., Qi, C., Yu, Q., Trapp, B., and Yuan, J. 2015. Activation of necroptosis in multiple sclerosis. Cell Rep. 10(11): 1836-1849

Opie, L.H. 1987. Myocardial ischaemia--metabolism and its modification. S. Afr. Med. J. 72(11): 740-747

Qin, D., Wang, X., Li, Y., Yang, L., Wang, R., Peng, J., Essandoh, K., Mu, X., Peng, T., Han, Q., Yu, K.J., and Fan, G.C. 2016. MicroRNA-223-5p and -3p Cooperatively Suppress Necroptosis in Ischemic/Reperfused Hearts. J. Biol. Chem. 291(38): 2024720259

Quarato, G., Guy, C.S., Grace, C.R., Llambi, F., Nourse, A., Rodriguez, D.A., Wakefield, 
R., Frase, S., Moldoveanu, T., and Green, D.R. 2016. Sequential Engagement of Distinct MLKL Phosphatidylinositol-Binding Sites Executes Necroptosis. Mol. Cell, 61(4): 589601

Re, D.B., Le Verche, V., Yu, C., Amoroso, M.W., Politi, K.A., Phani, S., Ikiz, B., Hoffmann, L., Koolen, M., Nagata, T., Papadimitriou, D., Nagy, P., Mitsumoto, H., Kariya, S., Wichterle, H., Henderson, C.E., and Przedborski, S. 2014. Necroptosis drives motor neuron death in models of both sporadic and familial ALS. Neuron, 81(5): 10011008

Schneider-Brachert, W., Tchikov, V., Neumeyer, J., Jakob, M., Winoto-Morbach, S., Held-Feindt, J., Heinrich, M., Merkel, O., Ehrenschwender, M., Adam, D., Mentlein, R., Kabelitz, D., and Schütze, S. 2004. Compartmentalization of TNF receptor 1 signaling: internalized TNF receptosomes as death signaling vesicles. Immunity, 21: 415-428

Skyschally, A., Gres, P., Hoffmann, S., Haude, M., Erbel, R., Schulz, R., and Heusch, G. 2007. Bidirectional role of tumor necrosis factor-alpha in coronary microembolization: progressive contractile dysfunction versus delayed protection against infarction. Circ. Res. 100(1): 140-146

Smith, C.C., Davidson, S.M., Lim, S.Y., Simpkin, J.C., Hothersall, J.S., and Yellon, D.M. 2007. Necrostatin: a potentially novel cardioprotective agent? Cardiovasc. Drugs. Ther. 21: $227-233$

Smith, D.K., and Zhang, C.L. 2015. Regeneration through Reprogramming Adult Cell Identity in Vivo. Am. J. Pathol. 185: 2619-2628

Strilic, B., Yang, L., Albarrán-Juárez, J., Wachsmuth, L., Han, K., Muller, U.C., Pasparakis, M., and Offermanns, S. 2016. Tumour-cell-induced endothelial cell necroptosis via death receptor 6 promotes metastasis. Nature, 536: 215-218

Sun, L., Wang, H., Wang, Z., He, S., Chen, S., Liao, D., Wang, L., Yan, J., Liu, W., Lei, X., and Wang, X. 2012. Mixed lineage kinase domain-like protein mediates necrosis signaling downstream of RIP3 kinase. Cell, 148: 213-227 
Szobi, A., Rajtik, T., Carnicka, S., Ravingerova, T., and Adameova, A. 2014. Mitigation of postischemic cardiac contractile dysfunction by CaMKII inhibition: effects on programmed necrotic and apoptotic cell death. Mol. Cell. Biochem. 388: 269-276

Szobi, A., Rajtik, T., and Adameova, A. 2016. Effects of necrostatin-1, an inhibitor of necroptosis, and its inactive analogue Nec-1i on basal cardiovascular function Physiol. Res. 65: 861-865

Takahashi, N., Duprez, L., Grootjans, S., Cauwels, A., Nerinckx, W., DuHadaway, J.B., Goossens, V., Roelandt, R., Van Hauwermeiren, F., Libert, C., Declercq, W., Callewaert, N., Prendergast, G.C., Degterev, A., Yuan, J., and Vandenabeele, P. 2012. Necrostatin-1 analogues: critical issues on the specificity, activity and in vivo use in experimental disease models. Cell Death Dis. 3: e437

Vanlangenakker, N., Berghe, T.V., Bogaert, P., Laukens, B., Zobel, K., Deshayes, K., Vucic, D., Fulda, S., Vandenabeele, P., and Bertrand, M.J. 2010. cIAP1 and TAK1 protect cells from TNF-induced necrosis by preventingRIP1/RIP3-dependent reactive oxygen species production. Cell Death Differ. 18: 656-665

Vanlangenakker, N., Bertrand, M.J.M., Bogaert, P., Vandenabeele, P., and VandenBerghe, T. 2011. TNF-induced necroptosis in L929 cells is tightly regulatedby multiple TNFR1 complex I and II members. Cell Death Dis. 2: e230

Wang, H., Sun, L., Su, L., Rizo, J., Liu, L., Wang, L.F., Wang, F.S., and Wang, X. 2014. Mixed lineage kinase domain-like protein MLKL causes necrotic membrane disruption upon phosphorylation by RIP3. Mol. Cell. 54: 133-146

Wen, S., Ling, Y., Yang, W., Shen, J., Li, C., Deng, W., Liu, W., and Liu, K. 2016. Necroptosis is a key mediator of enterocytes loss in intestinal ischaemia/reperfusion injury. J. Cell. Mol. Med. doi: 10.1111/jcmm.12987. [Epub ahead of print]

Wu, J., Huang, Z., Ren, J., Zhang, Z., He, P., Li, Y., Ma, J., Chen, W., Zhang, Y., Zhou, X., Yang, Z., Wu, S.Q., Chen, L., and Han, J. 2013. MLKL knockout mice demonstrate the indispensable role of MLKL in necroptosis. Cell. Res. 23: 994-1006

Xia, B., Fang, S., Chen, X., Hu, H., Chen, P., Wang, H., and Gao, Z. 2016. MLKL forms cation channels. Cell Res. 26(5): 517-528 
Zhang, T., Zhang, Y., Cui, M., Jin, L., Wang, Y., Lv, F., Liu, Y., Zheng, W., Shang, H., Zhang, J., Zhang, M., Wu, H., Guo, J., Zhang, X., Hu, X., Cao, C.M., and Xiao, R.P. 2016. CaMKII is a RIP3 substrate mediating ischemia- and oxidative stress-induced myocardial necroptosis. Nat. Med. 22(2): 175-182

Zhao, Z.Q., Nakamura, M., Wang, N.P., Wilcox, J.N., Shearer, S., Ronson, R.S., Guyton, R.A., and Vinten-Johansen, J. 2000. Reperfusion induces myocardial apoptotic cell death. Cardiovasc. Res. 45: 651-660 
Table 1. Necroptotic markers protein expression in the left ventricle of post-infarction failing hearts.

\begin{tabular}{|c|c|c|}
\hline & \multicolumn{2}{|c|}{ Left ventricle } \\
\hline \hline Group & C & HF \\
\hline \hline RIP1 & $1.707 \pm 0.048$ & $2.168 \pm 0.237$ \\
\hline RIP3 & $1.516 \pm 0.074$ & $2.162 \pm 0.297$ \\
\hline MLKL & $0.193 \pm 0.014$ & $0.355 \pm 0.027^{*}$ \\
\hline
\end{tabular}

The results are expressed as means \pm SEM from 5 and 9 hearts, and compared by Student's $t$ test. $\mathrm{C}$ - sham-operated group; $\mathrm{HF}$ - failing heart group. $* P<0.05$ vs $\mathrm{C}$. 
Table 2. Necroptotic markers protein expression in the left ventricle of isolated perfused hearts subjected to ischemia/reperfusion injury with or without ischemic preconditioning

\begin{tabular}{|c|c|c|c|}
\hline Group & C & IR & IPC \\
\hline \hline RIP1 & $\begin{array}{c}0.136 \pm \\
0.01 \mathrm{fi} 1\end{array}$ & $0.235 \pm 0.039$ & $0.211 \pm 0.030$ \\
\hline RIP3 & $0.021 \pm 0.004$ & $0.044 \pm 0.008^{*}$ & $0.046 \pm 0.008$ \\
\hline MLKL & $0.552 \pm 0.034$ & $0.681 \pm 0.039^{*}$ & $0.578 \pm 0.055$ \\
\hline
\end{tabular}

The results are expressed as means \pm SEM from 6 hearts. Statistical analysis was performed by 1-way ANOVA followed by Student's $t$-test. C - control perfused group; IR - group subjected to ischemia/reperfusion injury; IPC - group subjected to ischemic preconditioning followed by prolonged ischemia/reperfusion. $* P<0.05$ vs $\mathrm{C}$. 


\section{Figure Legends}

Figure 1. Schematic representation of necroptosis.

Binding of TNF- $\alpha$ to TNFR1 leads to the formation of complex I consisting of TNFR1, RIP1, TRADD, TRAF2, cIAP1/2 and CYLD. Polyubiquitination of RIP1 catalyzed by cIAP1/2 promotes the recruitment of TAK1 and NEMO and the activation of their downstream pathways such as NF- $\kappa \mathrm{B}$ signaling. Under conditions of increased RIP1 deubiquitination, for example due to deficient activity of cIAP1/2 or increased rate of CYLD-mediated deubiquitination, complex I instead internalizes and turns into complex II containing FADD, caspase- 8 and RIP1. When in the form of complex IIa, active caspase- 8 cleaves and inactivates RIP1 thus propagating apoptotic signaling. However, if caspase- 8 activity is inhibited, complex IIb with kinase-active RIP1 initiates necroptosis. In fact, RIP1 associates through a series of phosphorylation events with RIP3 and subsequently with MLKL forming the necrosome. Phosphorylated MLKL oligomerizes and translocates to the cytoplasmic membrane, where it induces permeabilization of the membrane, cell oncosis and finally membrane rupture.

Figure 2. Index of fractional shortening (FS) of sham-operated (C) and failing rat hearts (HF) on day 42 after the left anterior descending coronary artery ligation.

The results are expressed as mean \pm SEM, and compared by Student's $t$-test. $N=7$ per group. $* P<0.05$ vs. $C$. 
Figure 3.Post-ischemic recovery of left ventricular developed pressure (LVDP, in \% of preischemic values) in isolated-perfused rat hearts subjected to ischemia-reperfusion (IR) with and without prior ischemic preconditioning (IPC).

Each bar represents mean \pm SEM. Statistical analysis was performed by 1 -way ANOVA followed by Student's $t$-test. $N=9-12$ per group. $\mathrm{C}-$ control group; $* P<0.05$ vs. $C$. 


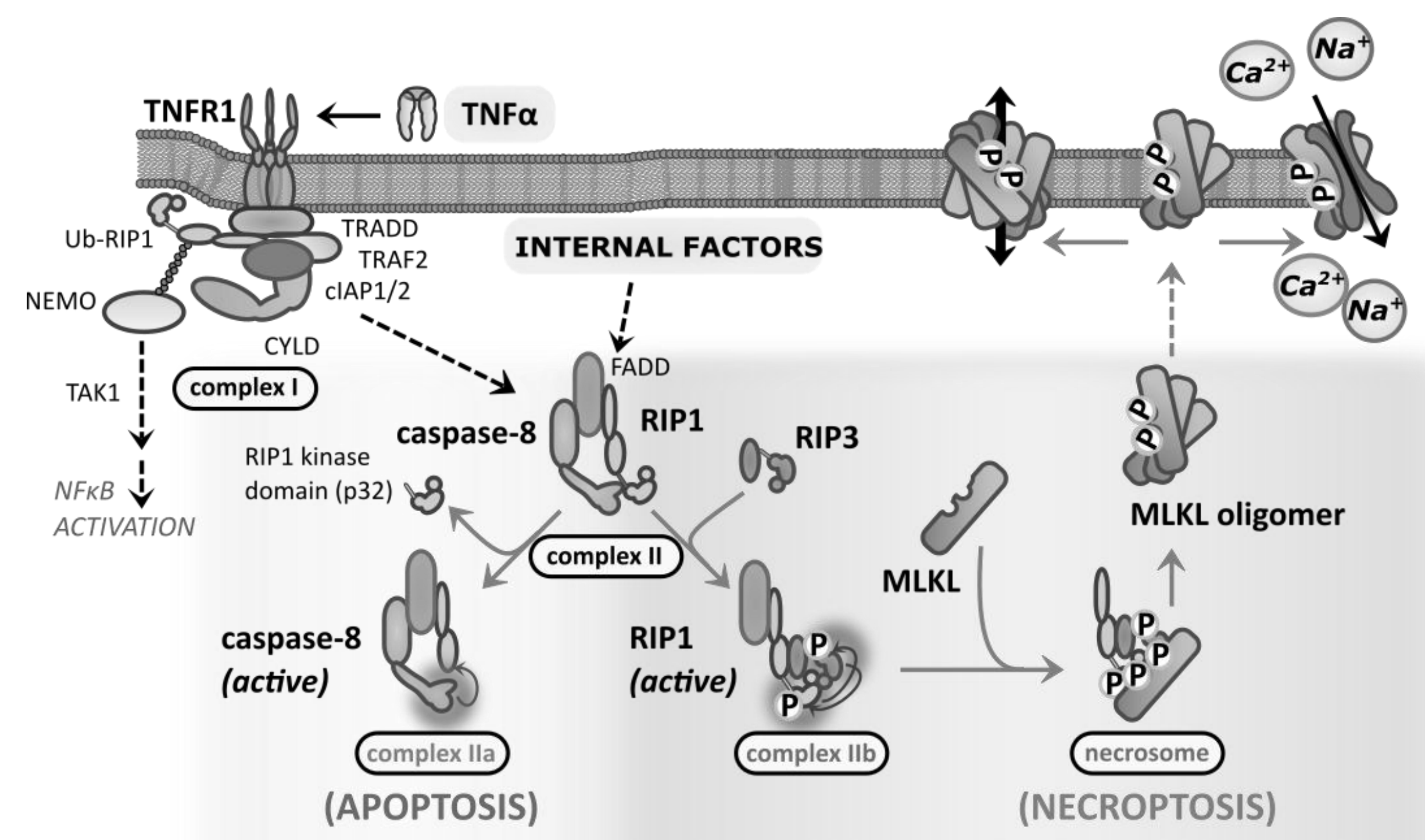




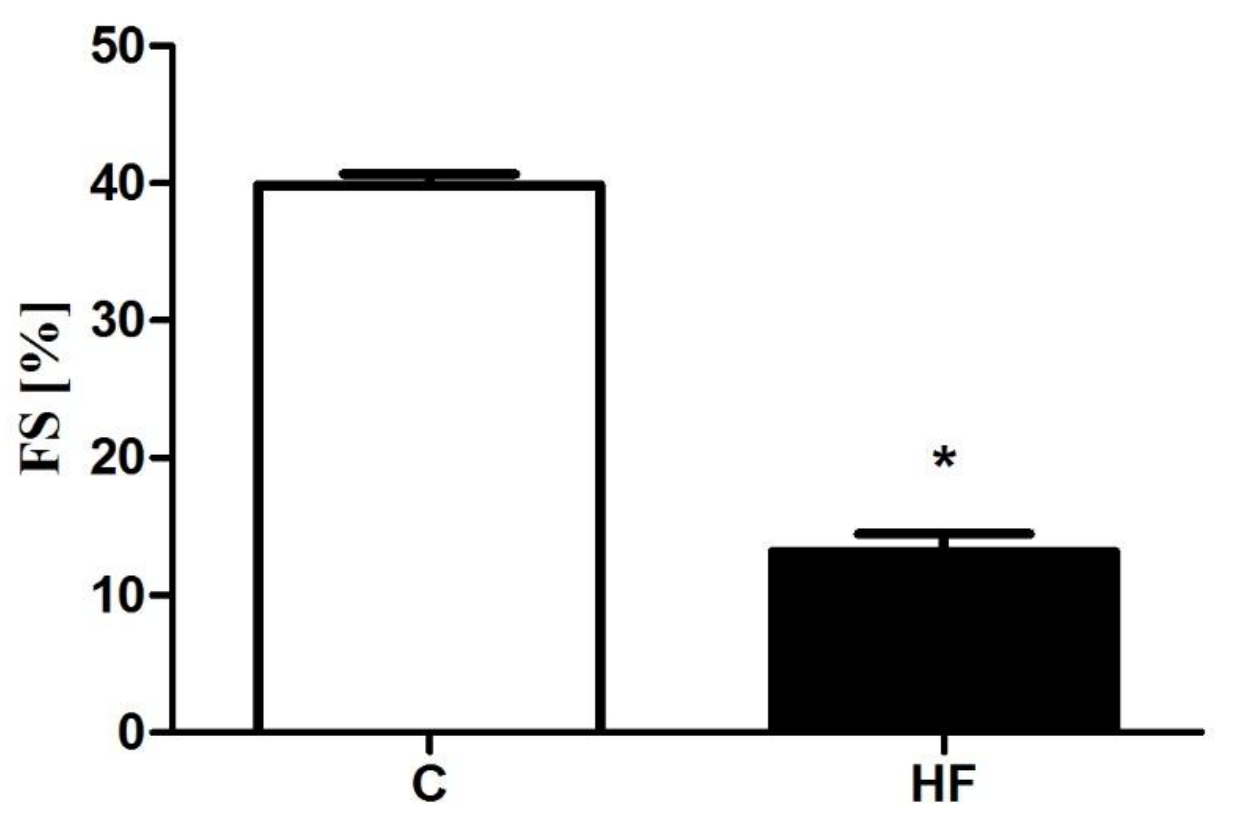




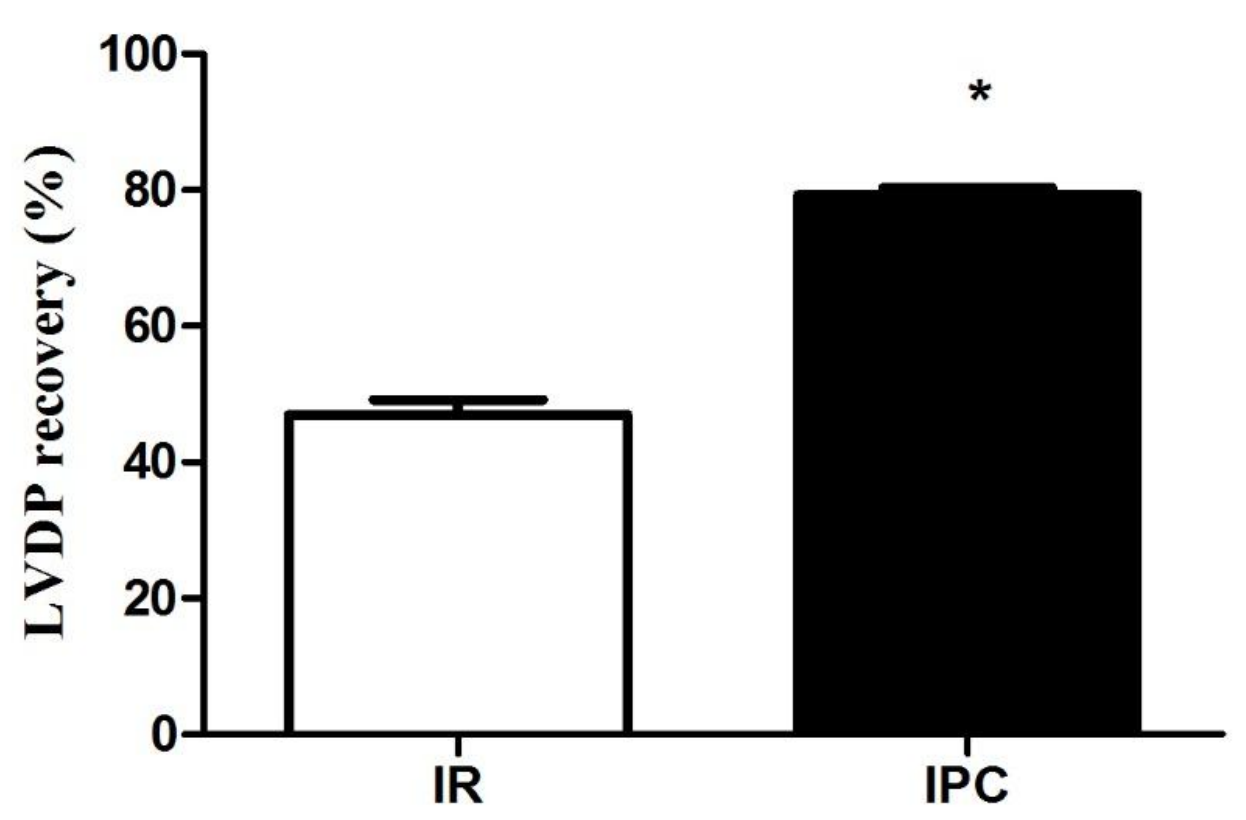

